\title{
The effect of increased number of cesarean on maternal and fetal outcomes
}

\author{
Ersin Çintesun ${ }^{1}$, Ragıp Atakan $\mathrm{Al}^{2}$ \\ ${ }^{1}$ Department of Obstetrics and Gynecology, Faculty of Medicine, Selcuk University, Konya, Turkey \\ ${ }^{2}$ Ataturk University, Erzurum, Turkey
}

\begin{abstract}
Objectives: The aim of this study was to evaluate the effects of multiple cesarean deliveries (CDs) on maternal-fetal morbidity and mortality rates.

Material and methods: This retrospective study included a total of 1,506 patients who underwent multiple CDs between January 2006 and May 2014. The patients were divided into two groups. One group consisted of patients with four or more CDs $(n=444)$ and a control group of patients with three CDs $(n=1,062)$. Both groups were analyzed for demographics, complications from multiple cesarean deliveries and perinatal outcomes.

Results: The mean age was higher in the study group $(p<0.001)$. Dense adhesion $(p<0.001)$, demand for tubal ligation $(p<0.001)$, the requirement of pelvic drainage $(p<0.001)$, duration of hospitalization $(p<0.001)$ and the requirement for blood transfusion ( $p=0.03$ ) was also significantly higher in the study group. Hemoglobin levels $(p=0.002)$ were significantly higher in the control group on the second postoperative day. Regarding perinatal morbidity; umbilical artery $\mathrm{pH}$ results $(p=0.003$ ) were significantly lower in the study group. There was no significant difference in the maternal and fetal mortality rates between both groups.

Conclusions: According to our study results, an increase in the number of cesarean sections increases maternal and fetal morbidity rates significantly. Therefore, we recommend decreasing the rate of primary cesarean deliveries by encouraging vaginal birth after $C D$. We also advocate the use of permanent contraceptive methods in patients with a high number of CD's. Further large-scale prospective results are required to establish a definitive conclusion.
\end{abstract}

Key words: cesarean delivery, intraoperative complications, morbidity, postoperative complications

\section{INTRODUCTION}

It is a major development for modern obstetric care that cesarean deliveries (CDs) have become a safe surgical procedure for both the mother and the newborn. In the $19^{\text {th }}$ century the CD's were indicated only in selected cases as the morality rate from the procedure rwas very high [1]. Recent advances in surgery and anesthesia techniques allow for $C D$ s to be performed with less risk. Yet, despite the safety, CD is still a major surgery that may lead to serious complications for mother and fetus. CD has many risks including anesthesia, blood transfusion, adjacent organ damage, embolism, neonatal morbidity and mortality, maternal infection, abnormal placental invasion, uterine rupture, and intra-abdominal adhesions [2, 3].

\section{OBJECTIVES}

In the present study, we aim to evaluate the effects of multiple CDs on maternal-fetal morbidity and mortality rates in a tertiary hospital where CDs are frequent.

\section{MATERIAL AND METHODS}

This study was approved by the University Ethics Committee and conducted in accordance with the principles of the Declaration of Helsinki. A written informed consent was obtained from each patient prior to $C D$.

A total of 1,506 patients underwent multiple CDs between January 2006 and May 2014. These patients were retrospectively analyzed using hospital records. The patients were divided into two groups. One group consisted 
of patients with four or more CDs $(n=444)$ while the control group consisted of patients with three CDs ( $n=1,062)$. Patients with multiple pregnancy, missing data, and inconsistent data were excluded from the study.

The study and control groups were analyzed in terms of the following variables:

- Preoperative variables: Number of CDs, presentation type, preoperative hemoglobin $(\mathrm{Hb})$ value $(\mathrm{mg} / \mathrm{dL})$, presence of placenta previa, abruptio placenta and chorioamnionitis.

- Intraoperative variables: Anesthesia type, dense adhesions, uterine incision type, tubal ligation, abnormal placental invasion, visceral organ injuries (bowel, bladder and ureter), salpingo-oophorectomy, uterine rupture (complete or incomplete), need for additional surgical techniques due to bleeding during CDs (uterine artery ligation, hypogastric artery ligation, uterine balloon tamponade (Bakri ${ }^{\circledR}$ balloon), peripartum hysterectomy).

- Postpartum variables: The length of hospitalization, postoperative $\mathrm{Hb}$ value $(\mathrm{g} / \mathrm{dL})$ on Day 2 , incision site infection, postpartum fever, endometritis, deep venous thrombosis, pulmonary embolism, re-laparotomy, disseminated intravascular coagulopathy (DIC), blood transfusion, and maternal death.

- Variables related to the newborn: Fetal weight, gender, Appearance, Pulse, Grimace, Activity, Respiration (APGAR) scores at the 1st minute, umbilical artery $\mathrm{pH}$, presence of meconium at birth, fetal anomalies, and admission to the pediatric intensive care.

\section{Inclusion criteria}

Chorioamnionitis was defined as the presence of two or more of the following clinical criteria: maternal fever $>38^{\circ} \mathrm{C}$, maternal tachycardia ( $>100$ beats/min), fetal tachycardia (> 160 beats/min), maternal fundal tenderness, maternal leukocytosis (WBC > 15,000 cells $/ \mathrm{mm}^{3}$ ), and maternal purulent vaginal discharge. Postpartum fever was defined as above $38^{\circ} \mathrm{C}$.

Patients with pulmonary thromboembolism who received treatment and were confirmed by spiral tomography were included in the study. Deep venous thrombosis was diagnosed using Doppler ultrasonography and clinical findings. Patients with deep vein thrombosis and pulmonary embolism were also defined as thromboembolism.

Incomplete uterine rupture where the old cesarean scar was dehisced but the uterine serosa remained intact and did not cause active bleeding and hemodynamic changes was defined as scar dehiscence. Complete rupture of the uterus including the visceral peritoneum and the presence of hemorrhagic fluid in the abdomen was defined as uterine rupture in this study.

For the diagnosis of abnormal placental invasions, the following criteria was used: 1) postoperative histopathologi- cal confirmation; 2) severe bleeding at the site of removal of the placenta, despite uterine contraction. The cases reported as placenta accreta, increta, and percreta in the surgical reports were all re-examined according to the aforementioned criteria, and were defined as placenta accreta syndrome.

Adhesions extending from the abdominal wall to the bladder, bowels, front wall of the uterus, and omentum which could not be dissected easily, and which were detected intraoperatively were defined as dense adhesions. Since the filmy/avascular adhesions were not routinely reported in the surgical reports, their data was not collected.

Visceral organ injury was defined as the entrance of intestine, bladder, and ureter cavities. Serosal defects were not identified as visceral organ injuries. Hospitalization length was calculated as the amount of day in the hospital after surgery.

Severe operative morbidity was defined as atony, placenta accreta syndrome, requirement of three units and more blood transfusion, DIC, pulmonary embolism, deep vein thrombosis, ablatio placenta, visceral organ injury, uterine rupture, endometritis, re-laparotomy, need for additional surgical techniques due to bleeding during CDs (uterine artery ligation, hypogastric artery ligation, uterine balloon tamponade (Bakri ${ }^{\circledR}$ balloon), peripartum hysterectomy). Mild surgical morbidity was defined as blood transfusion of up to two units, postoperative fever, and incision site infection and scar dehiscence.

\section{Surgical procedure}

Each patient was informed about method of administering anesthesia by the anesthesiologist and obstetrician immediately before surgery. Patient's preference was recorded and consent was signed. Suprapubic hair was depilated (if necessary) and Foley catheter was placed into the bladder. Before the cesarean section, the patient received $1 \mathrm{~g}$ cefazolin sodium or $600 \mathrm{mg}$ clindamycin parenterally for surgical prophylaxis. Antibiotic prophylaxis was not continued in patients who did not have any infection postoperatively.

We performed the standard cesarean section surgery protocol used in our clinic, which includes povidone-iodine for pre-operative skin cleaning as first step. Pfannenstiel incision was used and the subcutaneous tissue was released through a sharp dissection. The fascia was opened toward the lateral line after scissors were inserted $1 \mathrm{~cm}$ from the midline. After the rectus muscle and parietal peritoneum were opened using two fingers, the abdomen could be seen. The fetus was removed after a lower segment transverse incision (Kerr incision) and the umbilical cord was clamped. Umbilical artery blood gases were drawn for analysis. The uterus was removed from the abdomen and sutured with a single continuous stitch. Tubal ligation was performed using the Pomeroy technique based on the consent of the 
patient and her partner. Visceral and parietal peritoneum was routinely left open in our clinic, whereas the fascia was closed continuously with the no. 1 polyglactin suture. Drainage catheters were placed into the pelvic region in patients requiring close follow-up for postoperative bleeding. Furthermore, the skin was, sutured subcutaneously with $3 / 0$ polyglactin suture.

The Hb levels were measured preoperatively and postoperatively during the 48th hour. The patients were discharged after the second day in case there were no complications noted, and a follow-up visit was scheduled 10 days later.

\section{Statistical analysis}

Statistical analysis was performed using the Statistical Package for Social Sciences (SPSS) version 22.0 (IBM Corp., Armonk, NY, USA). Descriptive statistics were expressed in mean \pm standard deviation (SD), median (min-max), and number, if applicable. Data as analyzed using the Pearson Chi-Square test, Fisher Exact test, and Mann-Whitney U test. The odds ratios (ORs) was used to establish the proportional rate of differences between the study and control groups. A p value of $<0.05$ was considered statistically significant.

\section{RESULTS}

Of the 1,506 patients included in the study, 1,062 (70.5\%) were in the control group and 444 (29.5\%) were in the study group. 410 (27.2\%) patients underwent 4 CDs, whereas 34 (2.3\%) patients underwent 5 CDs.
The overall demographic and clinical findings of the groups are described in Table 1. The mean maternal age was higher in the study group $(p<0.001)$. There was no significant difference in the presentation, chorioamnionitis, uterine incision type, and preoperative $\mathrm{Hb}$ values between the groups $(p>0.05)$. Postoperative $\mathrm{Hb}$ levels were higher in the control group ( $p=0.002)$. The length of hospitalization after $C D$ s was higher in the study group $(p<0.001)$. Classical uterine incision was performed due to placenta previa totalis in four patients and leiomyoma located in the lower segment of the uterus in one patient. Abnormal placental invasions were detected intra-operatively in all of the placenta previa cases. The rate of regional anesthesia was similar in both groups. However, tubal ligation was significantly higher in the study group $(p<0.001)$. Tubal ligation could not be performed in a single patient in the control group and five patients in the study group due to dense adhesions. Pelvic drainage application was significantly higher in the study group $(p<0.001)$.

The causes of maternal morbidity are presented in Table 2. There was no significant difference between the groups in terms of placenta accreta syndrome, placenta previa, and ablatio placenta $(p>0.05)$. Placenta accreta syndrome was detected in 13 (37.1\%) of the placenta previa cases. Peripartum hysterectomy was performed in 13 patients, indicating no significant difference between the two groups ( $p>0.9$ ). Hysterectomy was performed in 13 patients. Subtotal hysterectomy was performed in 3 patients, one patient with uterine atony, and two with placenta ac-

Table 1. Demographic and clinical findings of the patients

\begin{tabular}{|c|c|c|c|c|}
\hline & $\begin{array}{l}\text { Control group } \\
(n=1062)\end{array}$ & $\begin{array}{l}\text { Study group } \\
(n=444)\end{array}$ & $\mathbf{p}$ & OR (95\% Cl) \\
\hline Maternal age & $31(18-59)$ & $32(19-51)$ & $<0.001$ & \\
\hline \multicolumn{5}{|l|}{ Presentation } \\
\hline Vertex & $990(93.2 \%)$ & $406(91.4 \%)$ & 0.35 & \\
\hline Non-vertex & $72(6.8 \%)$ & $38(8.6 \%)$ & 0.22 & \\
\hline Chorioamnionitis & $3(0.3 \%)$ & 0 & 0.56 & $0.35(0.01-6.60)$ \\
\hline \multicolumn{5}{|l|}{ Type of anesthesia } \\
\hline General anesthesia & $238(22.4 \%)$ & $86(19.4 \%)$ & \multirow{2}{*}{0.19} & \\
\hline Regional anesthesia & $824(77.6 \%)$ & $358(80.6 \%)$ & & \\
\hline Classical uterine incision & $2(0.2 \%)$ & $3(0.7 \%)$ & 0.15 & $3.60(0.60-21.6)$ \\
\hline Uterine T- incision & $8(0.8 \%)$ & $4(0.9 \%)$ & 0.75 & $1.19(0.35-3.99)$ \\
\hline Request for tubal ligation & $371(34.9 \%)$ & $258(58.1 \%)$ & $<0.001$ & $2.65(2.11-3.33)$ \\
\hline Pelvic drainage & $189(17.8 \%)$ & $140(31.5 \%)$ & $<0.001$ & $2.12(1.64-2.74)$ \\
\hline Preoperative $\mathrm{Hb}[\mathrm{g} / \mathrm{dL}]$ & $12.50(7-16.3)$ & $12.3(6.5-15.8)$ & 0.15 & \\
\hline Postoperative (Second day) Hb [g/dL] & $11.0(6.3-14.7)$ & $10.8(7.1-15.4)$ & 0.002 & \\
\hline $\mathrm{Hb}$ difference $[\mathrm{g} / \mathrm{dL}]$ & $1.40( \pm 1.16)$ & $1.48( \pm 1.19)$ & 0,889 & \\
\hline Length of hospitalization (days) & $2.8(2-78)$ & $3(2-15)$ & $<0.001$ & \\
\hline
\end{tabular}

The data was calculated as $\mathrm{n}(\%)$, median (min-max), mean ( \pm standard deviation). OR — odds ratio, $\mathrm{Cl}$ — confidence interval, Hb — hemoglobin. Bold values indicate statistically significant differences 
Table 2. Causes of maternal morbidity

\begin{tabular}{|c|c|c|c|c|}
\hline & $\begin{array}{l}\text { Control group } \\
(n=1062)\end{array}$ & $\begin{array}{l}\text { Study group } \\
\quad(n=444)\end{array}$ & $\mathbf{p}$ & OR $(95 \% \mathrm{Cl})$ \\
\hline Dense adhesion & 199 (18.7) & $122(27.5)$ & $<0.001$ & $1.64(1.26-2.12)$ \\
\hline Uterine rupture & $2(0.2)$ & $3(0.7)$ & 0.15 & $3.60(0.6-21.65)$ \\
\hline Uterine scar dehiscence & $13(1.2)$ & $10(2.3)$ & 0.13 & $1.85(0.8-4.27)$ \\
\hline Placenta accreta syndrome & $16(1.5)$ & $6(1.4)$ & 0.81 & $0.89(0.34-2.30)$ \\
\hline Placenta previa & $27(2.5)$ & $8(1.8)$ & 0.38 & $0.70(0.31-1.56)$ \\
\hline Ablatio placenta & $8(0.8)$ & $8(1.8)$ & 0.09 & $2.41(0.9-6.48)$ \\
\hline Uterine atony & $1(0.1)$ & $1(0.2)$ & 0.5 & $2.39(0.14-38.3)$ \\
\hline Hysterectomy & $9(0.8)$ & $4(0.9)$ & $>0.9$ & $1.06(0.3-3.47)$ \\
\hline Blood transfusion requirement & $57(5.4)$ & $37(8.3)$ & 0.03 & $1.60(1.04-2.46)$ \\
\hline$\leq 2$ erythrocyte transfusion & $30(52.6)$ & $23(62.3)$ & \multirow{2}{*}{0.29} & \\
\hline$\geq 3$ erythrocyte transfusion & $27(47.4)$ & $14(37.8)$ & & \\
\hline Bladder injury & $10(0.9)$ & $3(0.7)$ & 0.76 & $0.71(0.19-2.61)$ \\
\hline Bowel injury & 0 & $1(0.2)$ & 0.29 & $7.1(0.2-176.7)$ \\
\hline Ureteral ligation & $2(0.2)$ & 0 & $>0.9$ & $0.47(0.02-9.98)$ \\
\hline Postoperative fever $\left(38^{\circ} \mathrm{C}\right)$ & $4(0.4)$ & 0 & 0.326 & $0.26(0.01-4.92)$ \\
\hline Infection of incision & $5(0.5)$ & 0 & 0.33 & $0.21(0.01-3.91)$ \\
\hline Endometritis & $3(0.3)$ & 0 & 0.56 & $0.35(0.01-6.60$ \\
\hline Pulmonary embolism & $8(0.8)$ & $3(0.7)$ & $>0.9$ & $0.89(0.23-3.39)$ \\
\hline Deep vein thrombosis & 0 & $1(0.2)$ & 0.29 & $7.1(0.29-176.7)$ \\
\hline Thromboembolism & $8(0.9)$ & $4(0.9)$ & 0.75 & $1.19(0.35-3.99)$ \\
\hline Re-laparotomy & $3(0.3)$ & $1(0.2)$ & $>0.9$ & $0.79(0.08-7.68)$ \\
\hline $\mathrm{DIC}$ & $1(0.1)$ & 0 & $>0.9$ & $0.7(0.03-19.5)$ \\
\hline Maternal death & 0 & 0 & - & - \\
\hline
\end{tabular}

The data was calculated as $\mathrm{n}(\%)$. OR — odds ratio, $\mathrm{Cl}$ — confidence interval, DIC — disseminated intravascular coagulopathy. Bold values indicate statistically significant differences

creta syndrome. Total hysterectomy was performed in 10 patients, one patient with placental previa totalis, seven with placenta accreta, and two with uterine atony. Blood transfusion was required more often in the study group $(p=0.03)$. Dense adhesion was found to be higher in the study group $(p<0.001)$. A total of $53 \%$ of bladder injuries occurred in patients with placenta accreta syndrome. Both of the ureter ligations occurred due to the suturing of the extending incision during CD. There was no statistically significant difference in the uterine rupture and scar dehiscence rates between the groups $(p>0.05)$. In four patients, the postoperative intraabdominal bleeding required re-laparotomy. Maternal death was not observed in any group.

The patients with morbidity in each group are summarized in Table 3. The incidence of visceral organ injury and the rate of severe maternal morbidity were similar in both groups. However, mild maternal morbidity was significantly higher in the study group $(p=0.03)$.

Surgical treatments due to intraoperative bleeding are summarized in Table 4. A patient in the control group underwent uterine artery ligation due to placenta previa totalis and placenta increta. The uterus was preserved in this patient. In addition, hypogastric artery ligation was performed in two patients due to placenta previa totalis. In one case the uterus was preserved and the other was not. There was no statistically significant difference between two groups in terms of uterine artery ligation, hypogastric artery ligation, and Bakri ${ }^{\oplus}$ balloon application ( $p>0.05$ ). Unilateral salpingo-oophorectomy was performed on one patient per group who underwent a hysterectomy due to placenta accreta syndrome.

Fetal and neonatal data are shown in Table 5. No significant difference was found between the groups, except for the results of umbilical artery $\mathrm{pH}(\mathrm{p}=0.003)$. Umbilical artery data was not available in 278 patients and they were not included in the analysis. Ambiguous genitalia was found in one patient. This patient was excluded from the analysis. Male gender was more common in both groups. There was no statistically significant difference between the two groups in terms of stillbirth, meconium presence, fetal 
Table 3. Number of patients with morbidity according to the groups

\begin{tabular}{|l|c|c|c|c|}
\hline & $\begin{array}{c}\text { Control group } \\
(\mathbf{n = 1 0 6 2 )}\end{array}$ & $\begin{array}{c}\text { Study group } \\
(\mathbf{n = 4 4 4 )}\end{array}$ & $\mathbf{p}$ & OR (95\% Cl) \\
\hline Severe maternal morbidity & $56(5.3)$ & $24(5.4)$ & 0.88 & $1.03(0.63-1.69)$ \\
\hline Mild maternal morbidity & $48(4.5)$ & $32(7.2)$ & $\mathbf{0 . 0 3}$ & $0.18(0.11-0.30)$ \\
\hline Visceral organ injury & $10(0.9)$ & $4(0.9)$ & $>0.9$ & $0.95(0.29-3.06)$ \\
\hline
\end{tabular}

The data was calculated as $\mathrm{n}(\%)$. OR — odds ratio, $\mathrm{Cl}$ — confidence interval. Bold values indicate statistically significant differences

Table 4. Treatment due to intraoperative bleeding (except for hysterectomy)

\begin{tabular}{|l|c|c|c|c|}
\hline & $\begin{array}{c}\text { Control group } \\
(\mathbf{n = 1 0 6 2 )}\end{array}$ & $\begin{array}{c}\text { Study group } \\
(\mathbf{n = 4 4 4 )}\end{array}$ & $\mathbf{p}$ & OR (95\% CI) \\
\hline Uterine artery ligation & $1(0.1)$ & 0 & $>0.9$ & $0.7(0.03-19.5)$ \\
\hline Hypogastric artery ligation & $1(0.1)$ & $1(0.2)$ & 0.5 & $2.39(0.14-38.3)$ \\
\hline Bakriø balloon application & 0 & $2(0.5)$ & 0.08 & $12.0(0.57-250.6)$ \\
\hline
\end{tabular}

The data was calculated as $\mathrm{n}(\%) ; \mathrm{OR}$ — odds ratio, $\mathrm{Cl}$ — confidence interval. Bold values indicate statistically significant differences

\begin{tabular}{|c|c|c|c|c|}
\hline & $\begin{array}{l}\text { Control group } \\
(n=1062)\end{array}$ & $\begin{array}{l}\text { Study group } \\
(\mathrm{n}=444)\end{array}$ & p & OR (95\% CI) \\
\hline Newborn weight [g] & $2992(500-4700)$ & $2943(570-4300)$ & 0.12 & \\
\hline *Umbilical artery $\mathrm{pH}$ & 7.32 (7.00-7.58) & $7.30(6.68-7.51)$ & 0.003 & \\
\hline Stillbirth & $20(1.9)$ & $10(2.3)$ & 0.6 & $1.2(0.55-2.58)$ \\
\hline Meconium presence & $23(2.2)$ & $6(1.4)$ & 0.29 & $0.61(0.25-1.53)$ \\
\hline Fetal anomalies & $13(1.2)$ & $1(0.2)$ & 0.07 & $0.18(0.02-1.39)$ \\
\hline **APGAR score & $8(4-10)$ & $8(2-10)$ & 0.59 & \\
\hline Admission of NICU & $70(6.8)$ & 37 (8.6) & 0.22 & $1.28(0.85-1.95)$ \\
\hline \multicolumn{5}{|l|}{ Gender } \\
\hline Male & $564(53.1)$ & $225(50.7)$ & \multirow{2}{*}{0.5} & \\
\hline Female & 497 (46.8) & $219(49.3)$ & & \\
\hline
\end{tabular}

*For patients with data available; Group $1=847$, Group $2=381$

** Median (min-max)

The data was calculated as $\mathrm{n}(\%)$. OR — odds ratio, $\mathrm{Cl}$ — confidence interval, APGAR — appearance, pulse, grimace, activity, respiration; NICU — neonatal intensive care unit. Bold values indicate statistically significant differences

anomalies, APGAR scores in the 1st minute, and admission of neonate to pediatric intensive care unit $(p>0.05)$.

\section{DISCUSSION}

Cesarean delivery has shown a significant increase in both developed and developing countries, particularly in the last three decades [4]. In the United States, the rate of primary CD has increased by $68 \%$ and multiple CD by $178 \%$ over the past 30 years [5]. Researchers have addressed the close relationship between the increased number of CD's and maternal morbidity [6-9]. Some others have suggested that increased CDs do not put an additional risk for maternal and fetal morbidity $[10,11]$. In our study, mild maternal morbidity was found to be significantly higher in the group of patients with four or more CDs, whereas severe maternal morbidity did not have significant effect on visceral organ injury. In addition, the fetal umbilical artery $\mathrm{pH}$ was found to be significantly lower in the group with four or more CDs.

Uterine rupture that occurs during pregnancy or labor is a fatal complication for the mother and fetus. Uterine ruptures occur mostly in the area near scar formation post cesarean section. In a study, the incidence of uterine rupture was 5.1 in 100,000 births in scarred uterus, and 0.7 in a uterus without scars [12]. In a study conducted by Qublan et al. [13], they found a significant relationship between incomplete and complete uterine rupture and number of cesarean deliveries. In addition, the incomplete and complete rupture rates were found to be $2.2 \%$ and $1.3 \%$, respectively in patients with three or more CDs [13]. In our study, complete rupture and incomplete rupture rate in all patients was $0.33 \%$ and 
$1.52 \%$ respectively. Furthermore, complete rupture in the control and study groups was calculated to be $0.2 \%$ and $0.7 \%$, whereas incomplete rupture was $1.2 \%$ and $2.3 \%$ respectively. In our study, there was no significant difference between the groups in terms of complete and incomplete uterine rupture.

Adhesion is a condition that can occur after every abdominal operation. Adhesion may prolong the duration of the operation and may cause bladder or bowel injury, increased bleeding and delayed delivery of the fetus [14-16]. In many studies, the relationship between the frequency of $C D$ and adhesion has been observed [6, 10, 13, 17]. In one study, the rate of adhesion was determined as $7 \%$ in primary $C D$, whereas $65 \%$ in those with three CDs [18]. In other studies, the prevalence of adhesions was $12-46 \%$ in women with two CDs, and $26-75 \%$ in those with three CDs $[9,19-22]$. In our study, the rate of dense adhesion was $18.7 \%$ in the control group and $27.5 \%$ in the study group. The rate of dense adhesions was significantly higher in the four or more CDs group ( $p<0.001 ; O R=1.64$, [1, 26-2, 12]).

The relationship between bowel or bladder injury and frequency of $C D$ is controversial. Some of the studies did not show any increase in damage $[10,13]$, whereas some showed only bladder damage [23], some showed intestinal damage [24], and some showed damage in both [6, 25]. It has been observed that these risks did not show a linear increase with the rise in the number of CDs for the majority of the studies in which the risk of bladder and intestinal injury was significant $[6,23]$. Ozcan et al. [24] found that there was a significant correlation between the increase in cesarean number and bowel injury, but they did not find its relationship with bladder injury. In the study conducted by Tunc et al. [23], a statistically significant increase was found in the group that had their second $C D$, but no increase in the risk of linearity was observed as the number of CDs increased. The incidence of bowel, bladder and ureteral ligation was very rare and there was no significant difference between the groups. In the study group with four or more CDs, bowel injury due to dense adhesion was occurred in only one case. Ureter injury was seen in two cases that had their third CD in which the incision line was extended from lower segment to the vagina. There was no difference between either groups in terms of visceral organ injury (i.e., bladder, bowel, ureter).

One of the main risk factors created by the increased number of CDs was the dramatic increase in the frequency of placenta accreta syndromes. In a study conducted by Makoha et al. [14] who investigated patients with primary to seventh CDs, they reported that maternal morbidity increased until the third CD, but did not continue increasing after the third $\mathrm{CD}$. In addition, complications worsened, if there was history of placenta previa, placenta accreta and hysterectomy. In this study, placenta previa and accreta incidence increased with multiple CDs [14]. In a study conducted by Clark et al., the risk of placenta previa formation was $0.26 \%$ in a non-cesarean section, while the incidence of placenta previa increased as the number of CDs increased, reaching $10 \%$ over four CDs. In the same study, the prevalence of coexisting placenta previa and accreta was also investigated, in a patient with placenta previa who undergo no CD had a $5 \%$ risk of developing placenta accreta, whereas in patients with previous CDs this rate was $24 \%$ and increased to $67 \%$ for patients with their third and fourth CD [26]. Again, many researchers have argued that there is a close relationship between the number of cesarean deliveries and placenta previa [21, 27, 28]. Several researchers show that there is a close correlation between the number of cesarean deliveries and abnormal placental invasion [7]. In placenta previa patients, the risk of developing placenta accreta is 3-4\% in normal population and $50-67 \%$ in those with four or more CDs [29]. In our cohort of patients, placenta previa and invasion defects were more frequent than in population without CDs, and the rates of placenta previa and abnormal placental invasion (i.e., placenta accreta, increta, percreta) were similar in both groups.

In our study, postoperative maternal morbidity rates such as; stay in intensive care unit, fever, incisional infections, endometritis, pulmonary embolism, deep vein thrombosis, re-laparotomy, and DIC were similar in both groups. No maternal death was observed in either group.

In the study group, blood transfusion and pelvic drainage were found significantly higher. The higher rate of adhesions in the same group can be related to these results. In addition, the tendency for tubal ligation was significantly higher being $34.7 \%$ in the group with three CDs and $58.3 \%$ in the group with four or more CDs $(p<0.001)$. Tubal ligation varies among various regions depending on the beliefs of society and its traditions.

Neonatal outcomes may also vary between studies. In some studies, it was observed that the increase in the number of cesarean deliveries did not increase neonatal risks $[10,30]$. In other studies, the neonatal risk increased as the number of CDs increased [17,24]. In our study, fetal umbilical artery $\mathrm{pH}$ was found to be lower in the group with four or more CDs in terms of fetal birth weight, meconium presence, fetal anomalies, and APGAR score $(p=0.003)$.

The strength of our study is the relatively large data that has been evaluated in extensive detail. The limitations of our study include the retrospective design, lack of long-term follow up outcomes, evaluation of filmy adhesion data, and neonatal blood gas data in some fetuses.

\section{CONCLUSIONS}

In conclusion, an increasing number of $C D$ leads to a greater risk of maternal and fetal morbidity. Our study may be a guide for clinicians to consider the possibility that 
such complications may occur in patients with four or more $\mathrm{CDs}$. This can further be used to predict maternal-fetal complications and to optimize treatment. Furthermore, patients should be informed about the possible risks of multiple CDs and encouraged to use permanent contraceptive methods. In addition, the demand for permanent contraceptive methods such as tubal ligation may be increased with the increasing frequency of CDs.

\section{Acknowledgements}

No institution and organization contributed to this study.

\section{Conflict of interest}

The authors declare that they have no conflict of interest.

\section{REFERENCES}

1. Sewell JE. Cesarean section-a brief history. A brochure to accompany an exhibition on the history of cesarean section at the National Library of Medicine. Springer Reference. 1993;30, doi: 10.1007/springerreference 44168.

2. Gregory KD, Jackson $S$, Korst $L$, et al. Cesarean versus vaginal delivery: whose risks? Whose benefits? Am J Perinatol. 2012; 29(1): 7-18, doi: 10.1055/s-0031-1285829, indexed in Pubmed: 21833896.

3. Huang X, Lei J, Tan H, et al. Cesarean delivery for first pregnancy and neonatal morbidity and mortality in second pregnancy. Eur J Obstet Gynecol Reprod Biol. 2011; 158(2): 204-208, doi: 10.1016/j.ejogrb.2011.05.006, indexed in Pubmed: 21641102.

4. Betrán AP, Ye J, Moller AB, et al. The Increasing Trend in Caesarean Section Rates: Global, Regional and National Estimates: 1990-2014. PLoS One. 2016; 11(2): e0148343, doi: 10.1371/journal.pone.0148343, indexed in Pubmed: 26849801

5. Ananth CV, Friedman AM, Keyes KM, et al. Primary and Repeat Cesarean Deliveries: A Population-based Study in the United States, 1979-2010. Epidemiology.2017;28(4):567-574, doi: 10.1097/EDE.0000000000000658, indexed in Pubmed: 28346271.

6. Kaplanoglu M, Bulbul M, Kaplanoglu D, et al. Effect of multiple repeat cesarean sections on maternal morbidity: data from southeast Turkey. Med Sci Monit. 2015; 21:1447-1453, doi: 10.12659/MSM.893333, indexed in Pubmed: 25989945.

7. Marshall NE, Fu R, Guise JM. Impact of multiple cesarean deliveries on maternal morbidity: a systematic review. Am J Obstet Gynecol. 2011; 205(3): 262.e1-262.e8, doi: 10.1016/j.ajog.2011.06.035, indexed in Pubmed: 22071057

8. Cook JR, Jarvis S, Knight M, et al. Multiple repeat caesarean section in the UK: incidence and consequences to mother and child. A national, prospective, cohort study. BJOG. 2013; 120(1): 85-91, doi: 10.1111/14710528.12010, indexed in Pubmed: 23095012.

9. Uygur D, Gun O, Kelekci S, et al. Multiple repeat caesarean section: is it safe? Eur J Obstet Gynecol Reprod Biol. 2005; 119(2): 171-175, doi: 10.1016/j.ejogrb.2004.07.022, indexed in Pubmed: 15808374.

10. Rashid M, Rashid RS. Higher order repeat caesarean sections: how safe are five or more? BJOG. 2004; 111(10): 1090-1094, doi: 10.1111/j.1471-0528.2004.00244.x, indexed in Pubmed: 15383111.

11. Uyanikoglu $H$, Karahan MA, Turp AB, et al. Are multiple repeated cesarean sections really as safe? J Matern Fetal Neonatal Med. 2017; 30(4):482-485, doi: 10.1080/14767058.2016.1175426, indexed in Pubmed: 27072611.

12. Zwart JJ, Richters JM, Ory F, et al. Uterine rupture in The Netherlands: a nationwide population-based cohort study. BJOG. 2009; 116(8): 1069-78; discussion 1078, doi: 10.1111/j.1471-0528.2009.02136.x, indexed in Pubmed: 19515148.
13. Qublan HS, Tahat Y. Multiple cesarean section. The impact on maternal and fetal outcome. Saudi Med J. 2006; 27(2): 210-214, indexed in Pubmed: 16501678

14. Makoha FW, Felimban HM, Fathuddien MA, et al. Multiple cesarean section morbidity. Int J Gynaecol Obstet. 2004; 87(3): 227-232, doi: 10.1016/j.ijgo.2004.08.016, indexed in Pubmed: 15548394.

15. Morales KJ, Gordon MC, Bates GW. Postcesarean delivery adhesions associated with delayed delivery of infant. Am J Obstet Gynecol. 2007; 196(5): 461.e1-461.e6, doi: 10.1016/j.ajog.2006.12.017, indexed in Pubmed: 17466702.

16. Sikirica V, Broder MS, Chang E, et al. Clinical and economic impact of adhesiolysis during repeat cesarean delivery. Acta Obstet Gynecol Scand. 2012; 91(6): 719-725, doi: 10.1111/j.1600-0412.2012.01395.x, indexed in Pubmed: 22404156.

17. Yaman Tunc S, AgacayakE, SakS, et al. Multiple repeat caesarean deliveries: do they increase maternal and neonatal morbidity? J Matern Fetal Neonatal Med. 2017; 30(6): 739-744, doi: 10.1080/14767058.2016.1183638, indexed in Pubmed: 27125601.

18. Rossouw JN, Hall D, Harvey J. Time between skin incision and delivery during cesarean. Int J Gynaecol Obstet. 2013; 121(1): 82-85, doi: 10.1016/j.ijgo.2012.11.008, indexed in Pubmed: 23340272.

19. Tulandi T, Agdi M, Zarei A, et al. Adhesion development and morbidity after repeat cesarean delivery. Am J Obstet Gynecol. 2009; 201(1): 56.e1-56.e6, doi: 10.1016/j.ajog.2009.04.039, indexed in Pubmed: 19576375.

20. Soltan MH, Nuaim L, Khashoggi T, et al. Sequelae of repeat cesarean sections. International Journal of Gynecology \& Obstetrics. 1999; 52(2): 127-132, doi: 10.1016/0020-7292(95)02561-8.

21. Makoha FW, Felimban HM, Fathuddien MA, et al. Multiple cesarean section morbidity. Int J Gynaecol Obstet. 2004; 87(3): 227-232, doi: 10.1016/j.ijgo.2004.08.016, indexed in Pubmed: 15548394.

22. Morales KJ, Gordon MC, Bates GW. Postcesarean delivery adhesions associated with delayed delivery of infant. Am J Obstet Gynecol. 2007; 196(5): 461.e1-461.e6, doi: 10.1016/j.ajog.2006.12.017, indexed in Pubmed: 17466702

23. Yaman Tunc S, AgacayakE, Sak S, et al. Multiple repeat caesarean deliveries: do they increase maternal and neonatal morbidity? J Matern Fetal Neonatal Med. 2017; 30(6): 739-744, doi: 10.1080/14767058.2016.1183638, indexed in Pubmed: 27125601.

24. Ozcan S, Karayalcin R, Kanat Pe, et al. Multiple repeat cesarean delivery is associated with increased maternal morbidity irrespective of placenta accreata. European review for medical and pharmacological sciences. Epub 2015/07; 19(11): 1959-1963.

25. Silver RM, Landon MB, Rouse DJ, et al. National Institute of Child Health and Human Development Maternal-Fetal Medicine Units Network. Maternal morbidity associated with multiple repeat cesarean deliveries. Obstet Gynecol. 2006; 107(6): 1226-1232, doi: 10.1097/01. AOG.0000219750.79480.84, indexed in Pubmed: 16738145.

26. Clark SL, Koonings PP, Phelan JP. Placenta previa/accreta and prior cesarean section. Obstet Gynecol. 1985; 66(1): 89-92, indexed in Pubmed: 4011075.

27. Landon MB, Hauth $\mathrm{JC}$, Leveno $\mathrm{KJ}$, et al. National Institute of Child Health and Human Development Maternal-Fetal Medicine Units Network. Maternal and perinatal outcomes associated with a trial of labor after prior cesarean delivery. N Engl J Med. 2004; 351(25): 2581-2589, doi: 10.1056/NEJMoa040405, indexed in Pubmed: 15598960.

28. Gilliam M, Rosenberg D, Davis F. The likelihood of placenta previa with greater number of cesarean deliveries and higher parity. Obstet Gynecol. 2002; 99(6): 976-980, doi: 10.1097/00006250-200206000-00004, indexed in Pubmed: 12052584

29. Zaki ZM, Bahar AM, Ali ME, et al. Risk factors and morbidity in patients with placenta previa accreta compared to placenta previa non-accreta. Acta Obstet Gynecol Scand. 1998; 77(4): 391-394, doi: 10.1034/j.1600-0 412.1998.00015.x, indexed in Pubmed: 9598946.

30. Ma Lk, Liu Na, Bian Xm, et al. Pregnancy Outcomes of Repeat Cesarean Section in Peking Union Medical College Hospital. Chinese Medical Sciences Journal. 2009; 24(3): 147-150, doi: 10.1016/s10019294(09)60079-1. 